\title{
LIXIVIAÇÃO DE POTÁSSIO NA AVALIAÇÃO DA QUALIDADE FISIOLÓGICA DE SEMENTES DE AMENDOIM ${ }^{1}$
}

\author{
SILVELENA VANZOLINI²; JOÃO NAKAGAWA ${ }^{3}$
}

\begin{abstract}
RESUMO - O presente trabalho teve como objetivo investigar a possibilidade de se obter indicações sobre a qualidade fisiológica de sementes de amendoim através do teste de lixiviação de potássio, cuja eficiência foi avaliada comparativamente às informações fornecidas por outros testes de vigor e à emergência de plântulas em campo. Para tanto, utilizou-se dois lotes de sementes de amendoim da cultivar Tatu (peneira 20/64") que foram submetidos aos testes de germinação, primeira contagem de germinação, envelhecimento acelerado, condutividade elétrica (3 e 24 horas), emergência de plântulas em campo, índice de velocidade de emergência de plântulas, peso de matéria seca de plântulas e determinação do grau de umidade. Além destes, foram conduzidos estudos de lixiviação de potássio, cálcio e magnésio utilizando-se amostras de sementes fisicamente puras. A quantificação de potássio foi conduzida em fotômetro de chama e as de cálcio e magnésio em espectrofotometro de absorção atômica após 3, 6, 9, 12, 15, 18, 21, 24, 27 e 30 horas de embebição a $20^{\circ} \mathrm{C}$. As avaliações da lixiviação de potássio mostraram-se promissoras para a identificação de lotes com diferentes níveis de qualidade.
\end{abstract}

Termos para indexação: Arachis hipogaea, vigor, testes rápidos.

\section{POTASSIUM LEACHATE IN THE EVALUATION OF PEANUT SEED PHYSIOLOGICAL QUALITY}

\begin{abstract}
This study was carried out to investigate whether the physiological quality of peanut seeds should be evaluated using the potassium leachate test, which was compared with other physiological quality seed measurements. Two lots of peanut seeds, cultivar Tatu (20 mesh) were submitted to germination test, germination at first count, accelerated aging, electrical conductivity (3 and 24 hours), field seedling emergence, speed of emergence index, seedling dry weight, and seed moisture content. In addition, studies on potassium, calcium and magnesium leachate were carried out with pure seed samples. The amount of potassium leached was evaluated in a flame photometer and calcium and magnesium in an atomic absorption spectrophotometer after 3, 6, 9, $12,15,18,21,24,27$ and 30 hours of imbibition at $20^{\circ} \mathrm{C}$. The evaluations of the potassium leachate were promising for the identification of lots with different quality levels.

Index terms: Arachis hipogaea, vigor, rapid method.
\end{abstract}

\section{INTRODUÇÃO}

A rapidez na avaliação da qualidade das sementes permite a tomada de decisões rápidas, durante as operações de colheita, recepção, beneficiamento e comercialização, dimi-

\footnotetext{
${ }^{1}$ Aceito para publicação em 07/11/2003.

2 Eng ${ }^{\mathrm{a}}$ Agr ${ }^{\mathrm{a}}$, Dra., Profa. da Faculdade de Agronomia “Dr. Francisco Maeda”; Rodovia Jerônimo Nunes Macedo, km 1.

${ }^{3}$ Eng $^{\circ}$ Agr $^{\circ}$, Dr., Prof. Voluntário do Departamento de Produção Vegetal, FCA/UNESP; e-mail: secdamv@fca.unesp.br
}

nuindo riscos e prejuízos. Consequentemente, a pesquisa em tecnologia de sementes tem procurado desenvolver ou aperfeiçoar testes que possibilitem avaliar, com eficiência, a qualidade fisiológica das sementes, em período de tempo relativamente curto (Dias \& Marcos Filho, 1995).

A literatura tem mostrado que os testes rápidos de vigor, disponíveis para avaliação da qualidade das sementes, que produzem informação consistente sobre a qualidade fisiológica de sementes, são os associados com a determinação de atividades enzimáticas, respiratórias e integridade da membrana celular, como os testes de tetrazólio e de condutividade 
elétrica, respectivamente (Abdul-Baki \& Baker, 1973). O teste de lixiviação de potássio está baseado no mesmo princípio do teste de condutividade elétrica.

Woodstock et al. (1985) concluíram que as mensurações das quantidades de potássio e cálcio, lixiviados de sementes de algodão, foram promissoras como índices de avaliação da qualidade fisiológica da semente, enfatizando que os resultados obtidos da lixiviação de potássio eram mais consistentes que os do teste de condutividade elétrica.

O teste de lixiviação de potássio tem sido utilizado como um indicador da integridade da membrana celular, mostrando ser um índice rápido de avaliação do vigor de sementes de algumas espécies, como algodão (Woodstock et al., 1985), feijão (Barros et al., 1999), milho (Miguel \& Marcos Filho, 2002), soja (Dias et al., 1996; Custódio \& Marcos Filho, 1997) e tomate (Panobianco \& Marcos Filho, 2001).

Tendo em vista a carência de informações sobre testes de vigor em sementes de amendoim, o presente trabalho teve como objetivo verificar a potencialidade do teste de lixiviação de potássio para avaliação da qualidade fisiológica de sementes de amendoim.

\section{MATERIAL E MÉTODOS}

O trabalho foi desenvolvido no Laboratório de Análise de Sementes e no Laboratório de Relação Solo-Planta do Departamento de Produção Vegetal, na Faculdade de Ciências Agronômicas (FCA), da Universidade Estadual Paulista (UNESP), em Botucatu, SP.

Foram obtidos dois lotes de sementes de amendoim, do cultivar Tatu (peneira de crivo circular 20/64”), fornecidos pela Cooperativa dos Plantadores de Cana-de-Açúcar da Zona de Guariba (COPLANA), Jaboticabal, SP.

Os lotes de sementes com teores de água conhecidos e próximos, foram colocados em recipientes de vidro, para evitar trocas de umidade com o meio, e armazenados em câmara fria à temperatura de $5^{\circ} \mathrm{C}$ e umidade relativa de $80 \%$, até o início dos seguintes testes:

Teor de água das sementes: determinou-se pelo método de estufa, com $105 \pm 3^{\circ} \mathrm{C}$ por 24 horas (Brasil, 1992), utilizando-se duas repetições de 25 sementes. Os resultados foram expressos em porcentagem.

Lixiviação de K, Ca e Mg: utilizaram-se quatro repetições de 25 sementes puras. As sementes foram colocadas em copos plásticos de $200 \mathrm{~mL}$, onde foram adicionados $75 \mathrm{~mL}$ de água deionizada, sendo mantidos à temperatura de $20^{\circ} \mathrm{C}$. Os tempos de embebição estudados foram de 3, 6, 9, 12, 15,
18, 21, 24, 27 e 30 horas. Transcorrido o período de embebição, a solução que continha as sementes foi acondicionada em frascos de vidro, identificados e encaminhados para a determinação de íons. A determinação de potássio foi feita empregando-se o método de fotometria de chama e de cálcio e magnésio o método de espectrofotometria de absorção atômica. Os valores foram expressos em mg do íon. $\mathrm{kg}^{-1}$ de semente.

Germinação: realizado com oito repetições de 25 sementes previamente tratadas com $3 g$ de Rhodiauram (Thiram) por quilograma de sementes. Utilizou-se, como substrato, rolo de papel toalha (Germitest) umedecido com água na proporção de 2,5 vezes o peso do papel seco e o teste conduzido a $25^{\circ} \mathrm{C}$, segundo as recomendações das Regras para Análise de Sementes (Brasil, 1992). Os resultados foram expressos em porcentagem de plântulas normais.

Primeira contagem da germinação: realizado, conjuntamente com o teste de germinação, avaliando-se o número de plântulas normais no quinto dia após a semeadura. Os resultados foram expressos em porcentagem de plântulas normais.

Classificação do vigor de plântula: na primeira contagem da germinação ( $5^{\circ}$ dia), as plântulas normais bem desenvolvidas e morfologicamente perfeitas, sem rachaduras ou lesões foram computadas e classificadas como normais fortes (vigorosas). Na contagem final ( $\left.10^{\circ} \mathrm{dia}\right)$, todas as plântulas remanescentes foram avaliadas como normais ou anormais. As normais foram classificadas em fortes e em fracas. Foram consideradas como plântulas normais fracas àquelas que apresentaram algum problema em sua estrutura ou lesão, mas que não caracterizavam como anormalidade à plântula (Nakagawa, 1994).

Condutividade elétrica: utilizaram-se quatro repetições de 25 sementes puras colocadas em copos plásticos de 200mL, onde foram adicionados $75 \mathrm{~mL}$ de água deionizada, sendo mantidos à temperatura de $20^{\circ} \mathrm{C}$ (AOSA, 1983) por 3 e 24 horas. A leitura foi realizada em condutivímetro Digimed CD 21 e os resultados expressos em $\mu \mathrm{S} \mathrm{m}^{-1} \mathrm{~g}^{-1}$.

Envelhecimento acelerado: foi utilizado o método de caixas plásticas (gerbox adaptado). Foram colocadas pelo menos 250 sementes de amendoim, tratadas com Rhodiauram (Thiram), na tela suspensa no interior do gerbox, em uma camada única de sementes preenchendo-a totalmente, sem entrarem em contato com os 40mL de água contidos no seu interior. As caixas plásticas foram tampadas e mantidas à $42^{\circ} \mathrm{C}$ por 72 horas (Usberti, 1982), no interior de câmara climática. Após o período de envelhecimento, realizou-se o teste de 
germinação, utilizando-se oito repetições de 25 sementes, e com duas repetições de 25 sementes efetuou-se o monitoramento do teor de água, seguindo as metodologias já descritas.

Emergência de plântulas no campo: foram utilizadas 200 sementes para cada lote, em quatro repetições de 50 sementes, previamente tratadas com Rhodiauram (Thiram), 3g do produto comercial por kg de semente, que foram semeadas em sulco de 2,5 metros de comprimento a 0,05 metros de profundidade, distanciadas entre si de 0,30 metros. A contagem das plântulas emergidas foi feita em uma única vez, aos 21 dias após a semeadura (Nakagawa, 1994).

Índice de velocidade de emergência: conduzido em conjunto com o teste de emergência em campo, anotandose diariamente, no mesmo horário, o número de plântulas que apresentaram as folhas embrionárias visíveis. Ao final do teste, com os dados diários do número de plântulas normais, calculou-se o IVE empregando-se a fórmula proposta por Maguire (1962).

Peso de matéria seca de plântula: utilizando-se o teste instalado para avaliação da emergência de plântulas no campo, após 21 dias da semeadura, todas as plântulas foram arrancadas, colocadas em sacos de papel por repetição e, estes dentro de sacos de plástico por parcela, para evitar a perda de água. No laboratório, com auxílio de uma tesoura, a parte aérea das plântulas de amendoim foram separadas do sistema radicular e dos cotilédones persistentes, e somente as partes aéreas das plântulas de cada repetição foram utilizadas; o material de cada repetição foi colocado em saco de papel e levado para estufa com circulação de ar, mantida à temperatura de $80^{\circ} \mathrm{C}$, aí permanecendo por 24 horas. O material seco foi pesado, por repetição, em balança com precisão de $0,01 \mathrm{~g}$. O peso obtido foi dividido pelo número de plântulas que com- punha a repetição, obtendo-se o peso médio da matéria seca por plântula. A média aritmética das 4 repetições avaliadas constituiu o peso da matéria seca da plântula do tratamento (Nakagawa, 1994).

Procedimento estatístico: o experimento obedeceu ao delineamento inteiramente casualizado, composto de dois lotes. A análise da variância foi conduzida através do teste $\mathrm{F}$ e, quando este foi significativo, aplicou-se o teste de Tukey, a $5 \%$ de significância, para comparação das médias. As repetições e o número de sementes analisadas estão na metodologia de cada teste. Nenhuma variável sofreu transformação sendo expressos, nas Tabelas, os dados originais.

\section{RESULTADOS E DISCUSSÃO}

Os dados sobre a caracterização dos lotes empregados no experimento estão apresentados na Tabela 1 . O teor de água dos dois lotes empregados foi semelhante, dando maior segurança em afirmar que este fator não tenha influenciado os resultados dos testes empregados (Loeffler et al., 1988, Marcos Filho, 1999).

Todos os testes realizados em laboratório, inclusive o teste de germinação, diferenciaram os lotes, classificando o lote 1 como melhor. Embora a emergência de plântulas no campo tenha sido satisfatória, o lote 2 apresentou germinação abaixo do valor padrão para que as sementes possam ser comercializadas. O teste de germinação, realizado em substrato rolo de papel, pode não ter sido adequado para expressar o real potencial deste lote, visto que alguns fungos presentes no tegumento da semente, mesmo com o tratamento fungicida, persistiram. Como, estes tegumentos, ficaram em contato com as sementes e as plântulas recém emergidas, provocaram infecção secundária, diminuindo o número de

TABELA 1. Caracterização dos lotes de sementes de amendoim, cv. Tatu, pelos testes de teor de água (TA), teste de germinação (TG), primeira contagem da germinação (PCG), classificação do vigor de plântulas (Fortes), envelhecimento acelerado (EA), condutividade elétrica (CE), emergência de plântulas no campo (EC), índice de velocidade de emergência (IVE), peso de matéria seca de plântulas (MS).

\begin{tabular}{|c|c|c|c|c|c|c|c|c|c|c|}
\hline \multirow{3}{*}{ Lote } & \multicolumn{7}{|c|}{ Caracterização dos lotes em laboratório } & \multicolumn{3}{|c|}{ Caracterização dos lotes em campo } \\
\hline & TA & TG & PCG & Fortes & EA & $\mathbf{C E}-\mathbf{3 h}$ & CE - 24h & EC & IVE & MS \\
\hline & \multicolumn{5}{|c|}{$\%$} & \multicolumn{2}{|c|}{$\mu S . \mathrm{cm}^{-1} \cdot \mathrm{g}^{-1}$} & \multicolumn{2}{|c|}{$\%$} & g.planta ${ }^{-1}$ \\
\hline 1 & $7,1 a^{1}$ & $95 a$ & $60 a$ & $80 a$ & $88 \mathrm{a}$ & $2,23 a$ & $14,00 \mathrm{a}$ & $99 a$ & $7,25 a$ & $0,41 \mathrm{a}$ \\
\hline 2 & $7,5 \mathrm{a}$ & $50 \mathrm{~b}$ & $8 \mathrm{~b}$ & $29 \mathrm{~b}$ & $31 \mathrm{~b}$ & 8,81 b & $30,23 \mathrm{~b}$ & $80 \mathrm{~b}$ & $5,54 \mathrm{~b}$ & $0,38 \mathrm{a}$ \\
\hline $\mathrm{CV}$ & 2,10 & 12,39 & 19,89 & 13,49 & 17,65 & 14,33 & 15,61 & 6,35 & 7,17 & 14,15 \\
\hline
\end{tabular}

${ }^{1}$ Médias seguidas por letras diferentes, na coluna, diferem entre si pelo teste de Tukey a 5\%. 
plântulas normais. O uso de areia como substrato, provavelmente, teria evitado tal problema. O peso de matéria seca de plântula foi o único teste realizado em campo, onde não houve distinção dos lotes.

Os dados sobre lixiviação de K, Ca e Mg estão apresentados nas Tabelas 2, 3 e 4, respectivamente. Woodstock et al. (1985) encontraram resultados em que tanto a lixiviação de potássio, quanto de cálcio foram índices melhores para avaliar o vigor de sementes de algodão do que a quantidade total de eletrólitos extravasada, detectada na condutividade elétrica. Neste trabalho, a lixiviação de cálcio foi a que proporcionou resultados menos consistentes, não sendo um bom indicativo da qualidade de sementes de amendoim. Após 6 horas de embebição, foi possível diferenciar os dois lotes empregados, pela lixiviação de magnésio. Entretanto, os resultados ainda indicaram variações muito acentuadas nos coeficientes de variação.

O procedimento empregado para avaliar a lixiviação de potássio proveu resultados semelhantes aos demais testes (exceto o peso de matéria seca) empregados para caracterização dos lotes utilizados. É importante destacar que a lixiviação de potássio, que se baseia no mesmo princípio do teste de condutividade elétrica, foi tão eficiente quanto este na distinção dos lotes. O potássio foi o íon mais lixiviado dos elemen-

TABELA 2. Lixiviação de potássio de dois lotes de amendoim, cv. Tatu, em função do período de embebição.

\begin{tabular}{|c|c|c|c|c|c|c|c|c|c|c|}
\hline \multirow[b]{2}{*}{ Lote } & \multicolumn{10}{|c|}{ Período de embebição (horas) } \\
\hline & 3 & 6 & 9 & 12 & 15 & 18 & 21 & 24 & 27 & 30 \\
\hline & \multicolumn{10}{|c|}{ MgK.kg ${ }^{-1}$} \\
\hline 1 & $29,25 a^{1}$ & $39,50 a$ & $56,75 \mathrm{a}$ & $64,00 \mathrm{a}$ & $57,50 \mathrm{a}$ & $66,50 \mathrm{a}$ & $66,00 \mathrm{a}$ & $67,75 \mathrm{a}$ & $74,75 a$ & $75,00 \mathrm{a}$ \\
\hline 2 & $74,50 \mathrm{~b}$ & $109,75 \mathrm{~b}$ & $144,25 \mathrm{~b}$ & $150,75 \mathrm{~b}$ & $150,50 \mathrm{~b}$ & $149,00 \mathrm{~b}$ & $168,00 \mathrm{~b}$ & $186,00 \mathrm{~b}$ & $203,00 \mathrm{~b}$ & $197,50 \mathrm{~b}$ \\
\hline $\mathrm{CV}$ & 8,09 & 14,39 & 26,24 & 13,2 & 8,46 & 13,57 & 16,09 & 14,46 & 9,24 & 21,44 \\
\hline
\end{tabular}

${ }^{1}$ Médias seguidas por letras diferentes, na coluna, diferem entre si pelo teste de Tukey a 5\%.

TABELA 3. Lixiviação de cálcio de dois lotes de amendoim, cv. Tatu, em função do período de embebição.

\begin{tabular}{|c|c|c|c|c|c|c|c|c|c|c|}
\hline \multirow{3}{*}{ Lote } & \multicolumn{10}{|c|}{ Período de embebição (horas) } \\
\hline & 3 & 6 & 9 & 12 & 15 & 18 & 21 & 24 & 27 & 30 \\
\hline & \multicolumn{10}{|c|}{ MgCa.kg ${ }^{-1}$} \\
\hline 1 & $0,48 a^{1}$ & $0,47 a$ & $0,70 \mathrm{a}$ & $0,06 \mathrm{a}$ & $0,00 a$ & $0,00 \mathrm{a}$ & $0,09 a$ & $0,09 a$ & $0,10 \mathrm{a}$ & $0,20 \mathrm{a}$ \\
\hline 2 & $0,37 a$ & $1,07 \mathrm{a}$ & $1,57 \mathrm{~b}$ & $1,32 \mathrm{a}$ & $0,72 \mathrm{a}$ & $1,74 \mathrm{~b}$ & $1,26 \mathrm{a}$ & $2,53 \mathrm{~b}$ & $2,25 \mathrm{~b}$ & $2,00 \mathrm{~b}$ \\
\hline $\mathrm{CV}$ & 99,45 & 63,08 & 25,97 & 110,54 & 148,66 & 47,14 & 113,33 & 16,68 & 13,88 & 27,66 \\
\hline
\end{tabular}

${ }^{1}$ Médias seguidas por letras diferentes, na coluna, diferem entre si pelo teste de Tukey a 5\%.

TABELA 4. Lixiviação de magnésio de dois lotes de amendoim, cv. Tatu, em função do período de embebição.

\begin{tabular}{|c|c|c|c|c|c|c|c|c|c|c|}
\hline \multirow{3}{*}{ Lote } & \multicolumn{10}{|c|}{ Período de embebição (horas) } \\
\hline & 3 & 6 & 9 & 12 & 15 & 18 & 21 & 24 & 27 & 30 \\
\hline & \multicolumn{10}{|c|}{ MgMg.kg ${ }^{-1}$} \\
\hline 1 & $0,35 a^{1}$ & $0,32 \mathrm{a}$ & $0,45 a$ & $0,37 a$ & $0,28 \mathrm{a}$ & $0,10 \mathrm{a}$ & $0,56 \mathrm{a}$ & $0,58 a$ & $0,53 a$ & $0,91 \mathrm{a}$ \\
\hline 2 & $0,64 \mathrm{a}$ & $1,27 \quad b$ & $1,68 \mathrm{~b}$ & $1,82 \mathrm{~b}$ & $1,56 \mathrm{~b}$ & $2,05 \mathrm{~b}$ & $1,81 \mathrm{~b}$ & $2,33 \mathrm{~b}$ & $2,47 \quad b$ & $2,18 \mathrm{~b}$ \\
\hline $\mathrm{CV}$ & 68,62 & 37,40 & 64,12 & 31,40 & 52,88 & 16,81 & 45,64 & 30,19 & 30,15 & 33,91 \\
\hline
\end{tabular}

${ }^{1}$ Médias seguidas por letras diferentes, na coluna, diferem entre si pelo teste de Tukey a 5\%. 
tos avaliados, tendo sido possível diferir os lotes já com três horas de embebição. Segundo Carvalho \& Spina (1981), a fase inicial de absorção de água, por sementes de amendoim em germinação, a Fase I (Bewley \& Black, 1978), é de 1 a 2 horas. Tal fato é importante, pois revela a possibilidade de conseguir classificar lotes com diferentes níveis de vigor em períodos ainda menores do que os utilizados neste experimento, principalmente se forem utilizadas temperaturas mais elevadas para embeber as sementes. Neste sentido, Dias et al. (1996), utilizando 25 sementes puras de soja, embebidas por 60, 90, 120 e 150 minutos, à $30^{\circ} \mathrm{C}$ em $75 \mathrm{~mL}$ de água destilada, conseguiram separar os lotes em níveis de vigor já após 60 minutos de embebição. Miguel \& Marcos Filho (2002), avaliaram o teste de lixiviação de potássio em períodos de 30, 60, 90, 120 e 180 minutos. As sementes puras de milho embebidas em $75 \mathrm{~mL}$ de água destilada à $25^{\circ} \mathrm{C}$, por $30 \mathrm{minu}-$ tos, classificaram os lotes em diferentes níveis de qualidade fisiológica.

O emprego de dois lotes de qualidade fisiológica bastante distinta, não deve ser encarado como demérito ao resultado obtido neste experimento, visto que foi verificada a possibilidade da utilização do teste de lixiviação de potássio na discriminação de lotes de sementes de amendoim quanto a qualidade. Deve sim, ser encarado como um resultado inicial, que mostra a possibilidade de aperfeiçoar-se o trabalho, usando maior número de lotes com padrões comercializáveis e de se melhorar o teste para esta espécie, fazendo uso de procedimentos que combinem períodos menores que 3h de embebição, temperaturas maiores, variações no tamanho da amostra e no volume de água de embebição, entre outras alternativas, que possam indicar a metodologia mais adequada para esta espécie. Portanto, não se trata de um tema esgotado, no entanto, as avaliações da lixiviação de potássio mostraram-se com capacidade semelhante aos demais testes para a identificação de lotes com diferentes níveis de qualidade fisiológica, constituindo-se em um método simples e rápido para a avaliação da qualidade fisiológica das sementes de amendoim.

\section{CONCLUSÃO}

O teste de lixiviação de potássio tem potencial para classificar lotes de sementes de amendoim com diferentes níveis de qualidade fisiológica.

\section{AGRADECIMENTOS}

Os autores agradecem à Cooperativa dos Plantadores de Cana-de-Açúcar da Zona de Guariba (COPLANA), Jaboticabal/SP, por fornecer os lotes de sementes de amendoim utilizados no experimento.

\section{REFERÊNCIAS}

ABDUL-BAKI, A.A.; BAKER, J.E. Are changes in cellular organelles or membranes related to vigor loss in seeds. Seed Science and Technology, Zurich, v.1, p.89-125, 1973.

ASSOCIATION OF OFFICIAL SEED ANALYSTS. Seed vigour testing handbook. East Lansing: AOSA, 1983. 93p. (Contribution, 32).

BARROS, M.A.; OHSE, S.; MARCOS FILHO, J. Ion leakage as an indicator of vigor in field bean seeds. Seed Technology, Kentuky, v.21, p.44-48, 1999.

BEWLEY, J.D.; BLACK, M. Physiology and biochemistry of seeds in relation to germination. 1. Development, germination and growth. Berlin: Springer -Verlag, 1978. 306p.

BRASIL. Ministério da Agricultura. Regras para análise de sementes. Brasília: SNAD, DNDV, CLAV, 1992. 365p.

CARVALHO, N.M.; SPINA, I.A.T. Relações entre o tamanho, a velocidade de embebição de água e a velocidade de germinação de sementes de amendoim (Arachis hypogaea L.). In: REUNIÃO ANUAL DA SBPC, 33, Salvador, 1981. Ciência e cultura (Suplemento), Salvador, v.33, n.7, p.6, 1981.

CUSTÓDIO, C.C.; MARCOS FILHO, J. Potassium leakage test for the evaluation of soybean seed physiological quality. Seed Science and Technology, Zurich, v.25, n.3, p.549-564, 1997.

DIAS, D.C.F.S.; MARCOS FILHO, J. Testes de vigor baseados na permeabilidade das membranas celulares: II. Lixiviação de potássio. Informativo ABRATES, Curitiba, v.5, n.1, p.37-41, 1995.

DIAS, D.C.F.S.; MARCOS FILHO, J.; CARMELLO, Q.A.C. Potassium leakage test for the evaluation of vigour in soybean seeds. Seed Science and Technology, Zurich, v.24, p.7-18, 1996.

LOEFFLER, T.M.; TEKRONY, D.M.; EGLI, D.B. The bulk conductivity test as an indicator of soybean seed quality. Journal of Seed Technology, Springfield, v.12, n.1, p.37-53, 1988.

MAGUIRE, J.D. Speed of germination -aid in selection and evaluation for seedling and vigour. Crop Science, Madison, v.2, n.2, p.176-177. 1962.

MARCOS FILHO, J. Teste de envelhecimento acelerado. In: KRZYZANOWSKI, F.C.; VIEIRA, R.D.; FRANÇA NETO, J.B. (Ed.) Vigor de sementes: conceitos e testes. Londrina: ABRATES, 1999. cap.3, p.1-24. 
MIGUEL, M.V.C.; MARCOS FILHO, J. Potassium leakage and maize seed physiological potential. Scientia Agricola, Piracicaba, v.59, n.2, p. 315-319, 2002.

NAKAGAWA, J. Testes de vigor baseados na avaliação das plântulas. In: VIEIRA, R. D.; CARVALHO, N. M. (Ed.) Testes de vigor em sementes. Jaboticabal: FUNEP, 1994, p. 48-85.

PANOBIANCO, M.; MARCOS FILHO, J. Evaluation of the physiological potential of tomato seeds by germination and vigor tests. Seed Technology, Kentuky, v.23, p.149-159, 2001.

USBERTI, R. Relações entre teste de envelhecimento acelerado, potencial de armazenamento e tamanho de sementes em lotes de amendoim. Revista Brasileira de Sementes, Brasília, v.4, n.1, p.3134, 1982.

WOODSTOCK, L.W.; FURMAN, K.; LEFFLER, H.R. Relationship between weathering deterioration and germination, respiratory metabolism, and mineral leaching from cotton seeds. Crop Science, Madison, v.25, p.459-466, 1985. 